\title{
Application of Rapid Heat Separation and Injection in Detection of Biomarker Compounds
}

\author{
ZUODONG WANG $^{1,2}$, TING ZHANG $^{1,2,3}$,JUAN YANG $^{1,2,}$ \\ ${ }^{3}$, XIAOBIN LI $^{1,2}$, ZHONGPING Li ${ }^{1,2}$, MinGFENG ZHANG ${ }^{1,2}$ \\ ${ }^{1}$ Northwest Institute of Eco-Environment and Resources, \\ Chinese Academy of Sciences, Lanzhou 730000, China \\ ${ }^{2}$ Key Laboratory of Petroleum Resources, Gansu Province, \\ Lanzhou 730000, PR China \\ ${ }^{3}$ University of Chinese Academy of Science, Beijing, 10049, \\ China
}

Keywords:heat separation,injection,biomarker

After Soxhlet's extract and column chromatography separation, the light components in sediments such as source rocks and crude oil (n-alkanes below $\mathrm{nC}_{13}$ and fatty acids below $\mathrm{nC}_{6}$ ) will lose with the evaporation of the solvent, thus missing the geochemical information of these compounds in the analysis of GCMS ${ }^{[1]}$. Thermal desorption is a kind of technique that can resolve volatile and semivolatile organic compounds from the sample matrix or adsorbent and transfer to a gas chromatograph for analysis.

Using the principle of thermal desorption, a rapid thermal separation injection unit was designed, which was mounted on the MMI inlet of Agilent 7890B/7000B gas chromatography-triple quadrupole mass spectrometer. The volatile and semi-volatile organic compounds were separated quickly by heating temperature-programmed at the injector, and the gaseous volatiles were separated directly into the alloy chromatographic column (Frontier, Japan) together with the carrier gas. The thermal separation temperature of the injectior is lower than cracking temperature of the organic matter in the sample. A large number of pyrolysis experiments have proved that the soluble organic matter and kerogen in the source rock will crack above $300^{\circ} \mathrm{C}$, and many experiments have proved that the rapid thermal separation of most soluble organic matter in the source rock can be realized by keeping at $250^{\circ} \mathrm{C}$ for about $10 \mathrm{~min}$. The lowest carbon numbers that can be detected using this technique are: $\mathrm{n}$ alkanes $\mathrm{nC}_{4}$, fatty acids $\mathrm{nC}_{2}$, hopanes and steranes are the same as the extracts ${ }^{[2]}$.

Acknowledgements

This work was financially supported by the National Natural Science Foundation of China (Grant No. 41772133 and 41672138).

References

[1] Odden, W., 1999. Marine and petroleum geology 16, 747-770.

[2] Wang, Z., Liang, M., et al., 2016. Organic Geochemistry 102, 59-

66. 